\title{
50 UNDERSTANDING SELF-HARM IN YOUNG PEOPLE: AN EMOTIONAL UNBALANCE IN NEED FOR INTERVENTION
}

\author{
Marta Reis, Margarida Gaspar de Matos, \\ Lúcia Ramiro, Isa Figueira \\ Technical University of Lisbon, CMDT \& Aventura Social Project, \\ Cruz Quebrada, Portugal \\ E-mail: reispsmarta@gmail.com, mmatos@fmh.utl.pt, lisramiro@sapo.pt, \\ isapfigueira@gmail.com
}

\begin{abstract}
Self-harm behavior refers to the intentional self-destruction or alteration of body tissue without deliberate suicidal intent. Studies claimed self-harm as being associated to obsessive-compulsive characteristics and eating disorders, emotion-regulation functions when interpersonal distress occurs and physiological reactivity during a distressing task in association to social problem-solving deficits. Three national studies referring to young people will be presented. The main study's aim was to understand frequency of self-harm in Portuguese students and understanding the associations between self-harm and risk behaviors. A convenience sample of 206 was collected among high school and university students. The instrument used was a self-completed questionnaire: "Teens Self-Destructive Scale". A minority of self-harmers was found. Results suggested associations between self-harm, eating disorders and difficulties regarding self-regulation of emotions and that self-harm can be considered a non-adaptive and not successful personal strategy to manage emotions. Findings from the other two national studies will be referred. All together, these findings demonstrate the relevance of studies in this domain and helped producing guidelines in terms of therapeutic interventions. During the last decades, young people became more literate regarding health information and more aware of risk behaviors, but did not improve their literacy about emotions and how to deal with them. Are we in need for a "positive" approach to mental health promotion in young people?
\end{abstract}

Key words: protective factors, risk factors, self-harm, students.

\section{Introduction}

Self-harm behavior refers to the intentional self-destruction or alteration of body tissue without deliberate suicidal intent. Though systematic research on this behavior is still insufficient (Alfonso \& Dedrick, 2010), recent theoretical and empirical work has significantly advanced the understanding of this perplexing behavior (Jacobson \& Gould, 2007; ISSS, 2010). Self-harm is most prevalent among adolescents and young adults, typically involves cutting or carving the skin, and has a consistent presentation cross nations (Klonsky, 2011; Whitlock \& Knox, 2007). In general, studies suggest that $13 \%$ to $25 \%$ of adolescents and young adults surveyed in schools have some history of self-injury (Klonsky, 2011).

Across both clinical and community-based samples, research has shown that self-harm tends to have its onset in adolescence, commonly occurring during middle-to-late adolescence (13-15 years old) (Hamza, Stewart \& Willoughby, 2012), which emphasizes adolescence as a period of difficulties in emotional control and risk-taking, partly related to underlying biological changes (Moran, Coffey, Romaniuk, Olsson, Borschmann, Carlin, \& Patton, 2012) and sometimes hardened by traumatic 
episodes of life, for which they may not yet have sufficient personal and social skills to overcome them (Glassman, Weierich, Hooley, Deliberto \& Nock, 2007).

The most common kinds of self-harm behavior include cutting the skin (reported by $70 \%$ of individuals), scratching, burning, ripping or pulling skin or hair, pinching, hitting or breaking bones. Regarding areas of the body, the ones most referred are the arms, wrists, legs and belly, as are areas within easy reach and are also easily hidden (Nock, Gordon, Lloyd-Richardson, \& Prinstein, 2006).

Literature on self-harm prevalence and gender is mixed. While some studies show it to be more common among females, others suggest that it is as prevalent in males as in females. It is widely agreed, though, that self-harm is much more visible among females than among males (Croyle \& Waltz, 2007; Whitlock, Eckenrode, \& Silverman, 2006; Whitlock, Muehlenkamp, \& Eckenrode, 2008).

Most often, self-harming behavior is used to regulate intense negative emotion or to calm down quickly when feeling very emotional or overwrought. People who self-harm often have high sensitivity to emotion and difficulty handling negative feelings. Although the practice may dispel strong feelings in the short term, over time they are likely to experience intense shame or a sense of lack of control (Yates, 2004; Chapman, Gratz, \& Brown, 2006). Others use self-harming behavior to evoke emotion when they feel numb or dissociated. It may also be used as a means of self-control, punishment, or distraction. Some people report self-injuring to increase energy or improve mood but it may also be used to solicit attention from adults or peers, or to be part of a group (Whitlock, Muehlenkamp, \& Eckenrode, 2008).

Thoughts of engaging in self-harm typically occurs when the person is alone and experiencing negative thoughts or feelings (e.g., feeling anger, self-hatred, or numbness) in response to a stressful event (Nock, 2009). These thoughts and feelings immediately prior to engaging in self-harm have been reported consistently across studies and support the belief that self-harm is performed in most cases as a means of self-soothing or of help seeking (Klonsky, 2009; Muehlenkamp et al. 2009; Nock, 2009). Although people who engage in self-harm are more likely than people who don't to have drug and alcohol use disorders (Nock, Gordon, Lloyd-Richardson, \& Prinstein, 2006), self-harmers report using drugs or alcohol during less than five percent of those negative thoughts, suggesting that thoughts and behavior typically occur during periods of sobriety (Nock, 2009). Interestingly, when those thoughts occur, adolescents report simultaneously having thoughts of using drugs or alcohol and of engaging in bingeing and purging approximately $15 \%-35 \%$ of the time (Nock, 2009), suggesting that all these behaviors may serve the same function.

Individuals who engage in self-harming behavior may therefore have greater difficulty regulating their affective and social experiences than individuals who do not engage in self-harming behavior, and as a result are at increased risk for a variety of maladaptive coping behaviors (Hamza, Willoughby, \& Good, in press).

This study's aim was to understand frequency of self-harm in Portuguese students and understand the associations between self-harm and protective and risk behaviors. This was analyzed and compared in three studies.

\section{Methodology of Research}

\section{General Background of Research}

\section{Study 1: Health Behavior in School-aged Children (HBSC)}

The Health Behavior in School-aged Children (HBSC) is a World Health Organization (WHO) collaborative cross-national study (Currie, Roberts, Morgan, \& Smith, 2004) which is carried out every 4 years simultaneously in 43 countries or regions of Europe and North America in order to study school-aged behavior regarding health and risk behaviors in adolescence. Portugal is part of this group since 1996 (Currie, Hurrelmann, Settertobulte, Smith \& Todd, 2000; Matos et al., 2011).

Study 2: Online Study of Young People's Sexuality (OSYS) 
The Online Study of Young People's Sexuality (OSYS) is a Portuguese extension of the HBSC study. It is a nationwide study that assesses Sexuality and Risk behaviors-related knowledge, attitudes, and practices among the population aged 13-21 years old (Matos, Ramiro, Reis \& Equipa Aventura Social, 2012).

Study 3: Self-harm behavior in Portuguese students (SeHaS)

Self-harm behavior in Portuguese students $(\mathrm{SeHaS})$ is a study that assesses the frequency of self-harm in Portuguese students between 18 and 25 years old, how it affects their social life and understands the associations between self-harm and risk behaviors (Matos \& Equipa Aventura Social, in press).

\section{Sample of Research}

\section{Study 1: Health Behavior in School-aged Children (HBSC)}

The 2010 study provides national representative data of 5050 Portuguese adolescents, randomly chosen from those attending $6^{\text {th }}$ grade, $8^{\text {th }}$ grade (middle school) and $10^{\text {th }}$ grade (high school) This study used a subset of $8^{\text {th }}(\mathrm{n}=1594)$ and $10^{\text {th }}$ graders $(\mathrm{n}=1900)$. This sample included $53.6 \%$ girls and $46.4 \%$ boys, whose mean age was 14.94 years $(\mathrm{SD}=1.30)$. The majority of adolescents are of Portuguese nationality (94.2\%).

Study 2: Online Study of Young People's Sexuality (OSYS)

A sample of 396 was collected through an online questionnaire. It included $46.5 \%$ girls and $53.5 \%$ males, whose mean age was 16.8 years $(\mathrm{SD}=2.6)$. The majority of adolescents are of Portuguese nationality $(93.4 \%)$.

Study 3: Self-harm behavior in Portuguese students (SeHaS)

A convenience sample of 206 was collected among high school and university students. The sample included $87 \%$ women and $13 \%$ men, $13.1 \%$ high school and $86.9 \%$ college students with the mean age 20 years old $(\mathrm{SD}=1.83)$. The majority of students live with their family $(59.2 \%)$.

\section{Instrument and Procedures}

\section{Study 1: Health Behavior in School-aged Children (HBSC)}

Data were collected through a self-administered questionnaire, from the Portuguese sample of the Health Behavior in School-aged Children (HBSC), and all procedures were followed according to the international research protocol (Currie, Roberts, Morgan, \& Smith, 2004).

The 139 schools in the sample were randomly selected from the official national list of public schools, stratified by region: 52 schools in the North, 24 in the Centre, 41 in Lisbon and Tagus Valley, 7 in Alentejo and 6 in the Algarve. In each school, one class was randomly selected for each educational stage. After having received authorization, we solicited voluntary participants to fill out the questionnaires and explained the study's aim. The survey is nationwide and was conducted during the 2009/2010 school year for the Ministry of Portuguese Health and for the National Coordination for HIV/AIDS Infection by the Technical University of Lisbon.

In the questionnaire, which covers a wide range of questions about health and risk behaviors in adolescence, issues that relate to socio-demographic characteristics (gender, age, school attended, nationality), self-harming behavior (Yes/No and parts of the body most often chosen), protective factors (quality of life, resilience, self-regulation, skills, parental monitoring and family relationship) and risk factors (physical and psychological symptoms, drunkenness, drug use in the last month, walking with a gun in the last month, involvement in fights in last 12 months, suffering injury in last 12 months, going out with friends at night, feeling such sadness one cannot handle, and missing classes) were selected. 
The sample collection was conducted through an online questionnaire. Only young people who were between 13 and 21 years old at the time of the survey (May to June, 2011) were entitled to participate. Participation was anonymous and voluntary. Each person could participate only once and completing the questionnaire lasted between 15 and 30 minutes.

In the questionnaire, which covers a wide range of questions about sexual health and risk behaviors in adolescence, issues that relate to socio-demographic characteristics (gender, age, nationality), self-harm behavior (Yes/No, methods for self-harm, parts of the body most often chosen and emotions felt during self-harm), protective and risk factors (parental monitoring, drunkenness, drug use in the last month and involvement in fights in last 12 months) were selected.

Study 3: Self-harm behavior in Portuguese students (SeHaS)

This survey was conducted during the 2010/2011 school year by the Technical University of Lisbon. The sampling unit used in this survey was the class.

In the questionnaire it was selected issues that relate to socio-demographic characteristics (gender, age, school attended, residence), the description of self-harming experiences (knowing someone with self-harming behavior, time and kind of the first experience, kind of behaviors, part of the body most frequently hurt, emotions felt before, during and after) and the Teens Self-Destructive Scale were assessed through 76 items adapted from the original scale (Canevisio, P. et al, 2007). Students were asked to indicate their level of agreement with the statements using a five-point response format ( $1=$ never; $2=$ few times; $3=$ sometimes; $4=$ often; $5=$ always $)$.

The three studies had the approval of a scientific committee, the National Ethics Committee and the National Commission for Data Protection and followed strictly all the guidelines for human rights protection.

\section{Data Analysis}

The data were analysed using the Statistical Package for Social Sciences (version 20 for Windows). Descriptive statistics including frequencies, means and standard deviations were performed to give general descriptions of the data for the three studies. The associations between several independent variables (protective and risk factors) and the dependent variables (self-harming behavior) were ascertained using multivariate logistic regression analysis for study 1 and

2. Odds ratios (ORs) and 95\% confidence intervals (CIs) were calculated for all independent variables for studies 1 and 2. Exploratory data analysis, assessment of internal consistency, followed by an exploratory factor analysis of the Teens Self-Destructive Scale were conducted for study 3. Mann Whitney test was performed to examine differences in the Teens Self-Destructive Scale scores for the partial sample that mentioned having/not having had self-harming behavior in study 3 . For the three studies the level for statistical significance was set at $p<0.05$. Only significant results were discussed.

\section{Results of Research}

Study 1 - (HBSC)

\section{Self-harm Behavior}

The results showed $15.6 \%$ adolescents reported self-harming behavior in the last 12 months, mostly girls (57.6\%). The parts of the body most often chosen were: arms (52.9\%), legs (24.7\%) and belly (16.7\%). 


\section{Protective Factors Associated with Self-harm Behavior}

Using a multivariate logistic regression we obtained an adjusted model (Hosmer and Lemeshow $\chi^{2}=9,744 ; \mathrm{df}=8 ; \mathrm{p}=0.283$ ) and the regression equation explained $7 \%$ of the variance (Nagelkerke $\mathrm{R} 2=$ .078 ) and $85.8 \%$ of cases that showed having had self-harm behavior. In this model, the condition of "having had self-harming behavior" is explained by the variables quality of life (less quality of life with a 0.9 times greater likelihood of being in this group) [OR $0.86 ; 95 \%$ CI $0.76-0.98 ; p=0.019$ ], self-regulation (adolescents with less self-regulation with a probability 0.9 times higher to be in this group) [OR $0.86 ; 95 \%$ CI $0.75-0.99 ; p=0.029$ ], parental monitoring (those who reported fewer parental monitoring with a 0.8 times greater likelihood of being in this group) [OR $0.83 ; 95 \% \mathrm{CI}$ $0.74-0.93 ; p=0.001$ ], and family relationship (those who reported a family relationship less good, with a probability 0.7 times higher to be in this group) [OR $0.73 ; 95 \%$ CI $0.65-0.81 ; p=0.000$ ].

Although significant variables in the model only explain $8 \%$, and the association is not very strong to determine the dependent variable (having had self-harming behavior), this may be due to influential protective factors that are not evaluated in this research.

Table 1. Protective factors associated with having had self-harming behavior.

\begin{tabular}{lccccc}
\hline & $\boldsymbol{\beta}$ & $\mathrm{SE}$ & OR & $95 \%$ IC & $\boldsymbol{p}$ \\
\hline Quality of life (Kidscreen Scale) & -0.147 & 0.063 & 0.864 & $(0.764-0.976)$ & 0.019 \\
Resilience & -0.038 & 0.066 & 0.963 & $(0.846-1.097)$ & 0.570 \\
Self-regulation & -0.152 & 0.070 & 0.859 & $(0.750-0.985)$ & 0.029 \\
Skills & -0.070 & 0.060 & 0.933 & $(0.829-1.049)$ & 0.246 \\
Parental monitoring & -0.189 & 0.057 & 0.828 & $(0.741-0.925)$ & 0.001 \\
Family relationship & -0.320 & 0.056 & 0.726 & $(0.651-0.810)$ & 0.000 \\
\hline
\end{tabular}

OR: adjusted odds ratios for all other variables in the table; Cl: confidence interval

\section{Risk Factors Associated with Having Had Self-harming Behavior}

Using a multivariate logistic regression it was obtained an adjusted model (Hosmer and Lemeshow $\chi^{2}=11,337 ; \mathrm{df}=8 ; \mathrm{p}=0.183$ ) and the regression equation explained $7 \%$ of the variance (Nagelkerke R2 $=.133$ ) and $85 \%$ of cases that showed having had self-harming behavior. In this model, the condition of "having had self-harming behavior" is explained by the variables physical and psychological symptoms (those with more symptoms with a 1.4 times greater likelihood of being in this group) [OR 1.38; 95\% CI 1.24-1.53; $p=0.000$ ], involvement in fights in last 12 months (adolescents who reported more involvement in fights with a probability 1.1 times higher to be in this group) [OR 1.14; 95\% CI 1.02-1.27; $p=0.022]$, feeling such sadness one cannot handle (those who reported feeling more sadness with a 1.6 times greater likelihood of being in this group) [OR $1.60 ; 95 \%$ CI 1.42-1.79; $p=0.000]$, and missing classes (those who reported missing classes, with a probability 1.1 times higher to be in this group) [OR $1.14 ; 95 \%$ CI $1.03-1.26 ; p=0.011$ ].

Although significant variables in the model only explained $13 \%$, and the association was not very strong to determine the dependent variable (having had self-harming behavior), this may be due to influential protective factors that were not evaluated in this research.

Table 2. Protective factors associated with having had self-harming behavior

\begin{tabular}{lccccc}
\hline & $\boldsymbol{\beta}$ & SE & OR & 95\% IC & p \\
\hline Physical and psychological symptoms & 0.318 & 0.053 & 1.375 & $(1.239-1.525)$ & 0.000 \\
Drunkenness & -0.043 & 0.060 & 0.958 & $(0.851-1.078)$ & 0.476
\end{tabular}




\begin{tabular}{lccccc}
\hline & $\boldsymbol{\beta}$ & SE & OR & $95 \%$ IC & p \\
\hline Drug use in the last month & 0.017 & 0.051 & 1.018 & $(1.018-0.920)$ & 0.733 \\
Walking with a gun in the last month & 0.075 & 0.049 & 1.078 & $(0.980-1.186)$ & 0.122 \\
Involvement in fights in last 12 months & 0.131 & 0.057 & 1.140 & $(1.019-1.274)$ & 0.022 \\
Suffering injury in last 12 months & 0.028 & 0.052 & 1.029 & $(0.929-1.139)$ & 0.589 \\
Going out with friends at night & 0.112 & 0.058 & 1.119 & $(0.999-1.253)$ & 0.053 \\
Feeling such sadness one cannot handle & 0.468 & 0.059 & 1.596 & $(1.423-1.791)$ & 0.000 \\
Missing classes & 0.131 & 0.052 & 1.140 & $(1.030-1.261)$ & 0.011 \\
\hline
\end{tabular}

OR: adjusted odds ratios for all other variables in the table; Cl: confidence interval

Study 2-(OSYS)

\section{Self-harming Behavior}

The results showed $18 \%$ adolescents reported self-harming behavior in the last 12 months, mostly females $(54.5 \%)$. Of these, the methods more often mentioned for self-harm were cutting $(49.1 \%)$, squeezing (30.9\%) and burning (16.4\%) and body areas most often used were arms (70.9\%), legs $(32.7 \%)$ and belly (23.6\%). They mentioned feelings of anger / hostility (63.6\%), lack of hope for the future $(60 \%)$ and sadness $(58.2 \%)$ during the self-harming behavior.

\section{Protective and Risk Factors Associated with Having Had Self-harming Behavior}

Using a multivariate logistic regression it was obtained an adjusted model (Hosmer and Lemeshow $\chi^{2}=7.682 ; \mathrm{df}=7 ; \mathrm{p}=0.362$ ) and the regression equation explained $8 \%$ of the variance (Nagelkerke $\mathrm{R} 2=.075$ ) and $83.2 \%$ of cases that showed having had self-harming behavior. In this model, the condition of "having had self-harming behavior" was explained by the variable involvement in fights in last 12 months (adolescents who reported more involvement in fights with a probability 1.5 times higher to be in this group) [OR 1.47; 95\% CI 1.08-1.99; $p=0.012$ ].

Although significant variables in the model only explained $8 \%$, and the association was not very strong to determine the dependent variable (having had self-harming behavior), this may be due to influential protective factors that were not evaluated in this research.

Table 3. Protective and risk factors associated with self-harm behavior.

\begin{tabular}{lccccc}
\hline & $\boldsymbol{\beta}$ & SE & OR & $95 \%$ IC & p \\
\hline Parental monitoring & -0.296 & 0.161 & 0.744 & $(0.543-1.019)$ & 0.065 \\
Drunkenness & 0.022 & 0.182 & 1.023 & $(0.715-1.462)$ & 0.903 \\
Drug use in the last month & -0.484 & 0.289 & 0.616 & $(0.350-1.087)$ & 0.094 \\
$\quad$ Involvement in fights in last 12 months & 0.388 & 0.155 & 1.474 & $(1.089-1.996)$ & 0.012 \\
\hline
\end{tabular}

Study 3- (SeHaS)

\section{Knowing Someone with Self-harming Behavior}

$15.2 \%$ of the total sample referred that they knew of someone with self-harming behavior. Of these, $25.4 \%$ and $4.7 \%$ reported knowing of some friends and some family (respectively) with self- 
56 harming behavior. $18.8 \%$ of friends used sharp objects for cutting arms or wrists and $3.4 \%$ knew of family members who had got drunk, cut or scratched themselves as a self-harming behavior.

\section{Self-harming Behavior}

As for participants self-harming behavior, $10.4 \%$ adolescents reported having done so in the last 12 months, mostly females $(85.7 \%)$. They also reported their first self-harming behavior to have occurred between 12 and 23 years old, having used sharp objects $(38.1 \%)$ or beating $(23.8 \%)$ and biting (9.5\%) themselves. As for other experiences of self-harm, the methods more often mentioned were cutting or scratching themselves $(38.1 \%)$, getting drunk or knocking on objects $(33.3 \%)$, causing bruises $(23.8 \%)$, biting (19\%) and burning, choking or piercing and taking drugs $(14.3 \%)$. As body areas, the most often used were arms and wrists (38.1\%), legs (23.8\%) and belly (14.3\%). They mentioned feelings of anger (80\%), sadness $(60 \%)$, anxiety (35\%), disgust $(25 \%)$ and fear $(20 \%)$ before the self-harming behavior. During self-harm the most reported feelings were anger $(50 \%)$, sadness $(35 \%)$ and fear $(30 \%)$ and after sadness $(55 \%)$, relief $(50 \%)$ and fear $(35 \%)$.

\section{Principal Components Factor Analysis with Oblique Rotation of "Teens Self Destructive Scale"}

The 76 items of Teens Self Destructive Scale were subjected to principal components factor analysis with oblique rotation. The items with communality $<.40$, and an extraction of 4 factors were suppressed.

The remaining 35 items were again subjected to a principal components factor analysis with oblique rotation, which revealed an extraction with 4 factorial factors, explaining $40 \%$ of variance (see table 4).

Table 4. Factor analysis of Teens Self-Destructive Scale.

\begin{tabular}{|c|c|c|c|c|}
\hline \multirow{2}{*}{ Factor Analysis } & \multicolumn{4}{|c|}{ Factors } \\
\hline & $\begin{array}{c}\text { Risk } \\
\text { behaviors }\end{array}$ & $\begin{array}{l}\text { Negative } \\
\text { feelings }\end{array}$ & $\begin{array}{l}\text { Social } \\
\text { support }\end{array}$ & Detachment \\
\hline Engaging in Fights (beating/ assaulting someone) & 0.673 & & & \\
\hline Running away from home & 0.609 & & & \\
\hline Attempting suicide & 0.603 & & & \\
\hline Thinking about running away from home & 0.586 & & & \\
\hline Breaking objects on purpose when angry & 0.580 & & & \\
\hline Making competitions / speeding car / bike races & 0.564 & & & \\
\hline Making threats & 0.560 & & & \\
\hline Using hard drugs (eg. cocaine, ecstasy, heroin) & 0.539 & & & \\
\hline $\begin{array}{l}\text { Going to the emergency room / clinic as a result of self- } \\
\text { harming behavior }\end{array}$ & 0.506 & & & \\
\hline $\begin{array}{l}\text { Having sexual intercourse with different people at the } \\
\text { same time (if you have never had sexual intercourse } \\
\text { respond imagining what you would do in this situation) }\end{array}$ & 0.496 & & & \\
\hline $\begin{array}{l}\text { Hurting oneself on purpose when I argue with other people } \\
\text { (parents, friends, etc.) }\end{array}$ & 0.483 & & & \\
\hline
\end{tabular}




\begin{tabular}{|c|c|c|c|c|}
\hline \multirow[b]{2}{*}{ Factor Analysis } & \multicolumn{4}{|c|}{ Factors } \\
\hline & $\begin{array}{c}\text { Risk } \\
\text { behaviors }\end{array}$ & $\begin{array}{l}\text { Negative } \\
\text { feelings }\end{array}$ & $\begin{array}{l}\text { Social } \\
\text { support }\end{array}$ & Detachment \\
\hline Inducing vomit & 0.461 & & & \\
\hline Taking soft Drugs & 0.432 & & & \\
\hline Thinking that nobody understands me & & 0.681 & & \\
\hline Being afraid & & 0.673 & & \\
\hline Feeling anxious & & 0.662 & & \\
\hline Worrying for long periods of time when I have a problem & & 0.660 & & \\
\hline Feeling alone & & 0.657 & & \\
\hline Feeling angry & & 0.643 & & \\
\hline Feeling bored & & 0.616 & & \\
\hline Getting angry with myself if I cannot solve a problem & & 0.567 & & \\
\hline $\begin{array}{l}\text { Thinking about not being able to sort things out on my own } \\
\text { in certain situations }\end{array}$ & & 0.516 & & \\
\hline Arguing with my parents & & 0.425 & & \\
\hline $\begin{array}{l}\text { Thinking about dropping school or abandoning my job } \\
\text { without a valid reason }\end{array}$ & & 0.417 & & \\
\hline Avoiding situations that trigger fear in me & & 0.414 & & \\
\hline Talking about my personal problems to friends & & & 0.807 & \\
\hline Sharing my problems with other people & & & 0.796 & \\
\hline Talking to someone when I'm not ok & & & 0.791 & \\
\hline Calling /being with friends when I don't know what to do & & & 0.672 & \\
\hline Having a meeting place to be with my friends & & & 0.440 & \\
\hline $\begin{array}{l}\text { Being indifferent when I am reprimanded / at school or } \\
\text { work }\end{array}$ & & & & 0.757 \\
\hline $\begin{array}{l}\text { Being indifferent when I have bad grades / make mistakes } \\
\text { at work }\end{array}$ & & & & 0.720 \\
\hline Practicing a team sport & & & & 0.525 \\
\hline Not talking to my parents when I'm physically indisposed & & & & 0.523 \\
\hline $\begin{array}{l}\text { Waiting for a problem to resolve itself when I cannot } \\
\text { resolve it on my own }\end{array}$ & & & & 0.438 \\
\hline Explained variance & 16,84 & 9,16 & 8,31 & 6,04 \\
\hline
\end{tabular}

The first factor included 13 items related to risk behaviors, and explained $16.8 \%$ of the variance. The second and third factor grouped 12 and 5 items related to negative feelings and social support and explained $9.2 \%$ and $8.3 \%$ of variance, respectively. Finally, the fourth factor grouped 5 items 
that had to do with detachment, with $6 \%$ of the explained variance. Thus, the factor that was most relevant to explain the variance of $16.8 \%$ was risk behaviors.

\section{Differences in the Teens Self-Destructive Scale Scores \\ for the Partial Sample that Mentioned Having/Not Having Had Self-harming Behavior}

A partial sample of 21 students was derived from the total sample of self-harmers (considering all students that referred having ever experienced self-harming behavior) and was paired with another partial sample of 21 students with the same age and gender but not self-harmers (considering all students that referred having never experienced self-harming behavior), making a total of 42 students.

Table 5. Differences in the Teens Self-Destructive Scale scores for the partial sample that mentioned having/not having had self-harming behavior.

\begin{tabular}{|c|c|c|c|c|c|c|c|}
\hline & \multicolumn{2}{|c|}{$\begin{array}{l}\text { Having had self- } \\
\text { harming behavior } \\
(\mathrm{N}=21)\end{array}$} & \multicolumn{2}{|c|}{$\begin{array}{l}\text { Not having had } \\
\text { self-harming } \\
\text { behavior }(N=21)\end{array}$} & \multicolumn{2}{|c|}{$\begin{array}{c}\text { Total } \\
(\mathrm{N}=42)\end{array}$} & \multirow[t]{2}{*}{$U$} \\
\hline & M & SD & M & SD & M & SD & \\
\hline Teens Self-Destructive Scale & 82.70 & 10.73 & 76.10 & 6.98 & 79.40 & 9.54 & $125,000^{*}$ \\
\hline Risk Behavior (subscale) & 18.40 & 5.17 & 15.40 & 2.23 & 16.90 & 4.22 & $121,500^{*}$ \\
\hline Negative feelings (subscale) & 35.10 & 5.21 & 32.00 & 5.79 & 33.59 & 5.66 & 163,000 \\
\hline Social support (subscale) & 18.00 & 3.86 & 17.55 & 3.87 & 17.78 & 3.82 & 198,000 \\
\hline Detachment (subscale) & 10.95 & 2.42 & 11.15 & 2.08 & 11.05 & 2.24 & 182,500 \\
\hline
\end{tabular}

Comparing the 2 groups by using the non parametric Man Whitney test, there were no statistically significant differences for negative feelings, social support and detachment. Statistical significant differences occurred regarding the global Teens Self-Destructive Scale and the risk behavior subscale.

\section{Discussion}

These cross-sectional studies of young people examined prevalence as well as protective and risk behaviors correlates associated with reporting self-harming behavior. The findings showed that some demographic factors, some risk factors and the lack of some protective factors associated with self-harming behavior vary significantly: girls/women and students in lower grade levels were most likely to report self-harming behavior. Moreover, findings showed that there is a significant overlap in the modifiable protective and risk factors associated with self-harming behavior that can be targeted for future research and prevention strategies. These are: involvement in fights, physical and psychological symptoms (e.g. headaches, depression), sadness, missing classes and lower levels of quality of life, parental monitoring and family relationship.

Regarding the demographic characteristics associated with self-harming behavior, it was clear that girls/women were at the highest risk, as were those who engaged in or were exposed to other high-risk behaviors. This was not surprising given previous researches that showed that being female, having behavior problems, somatic problems, substance use and aggressive behavior were associated with self-harming behavior in young people (Croyle \& Waltz, 2007; Whitlock, Eckenrode, \& Silverman, 2006; Whitlock, Muehlenkamp, \& Eckenrode, 2008).

Prevalence rates of $15.6 \%, 18 \%$ and $10.4 \%$ were consistent with other studies and suggest that self-harming behavior in this population should be given serious consideration. Most other studies reported a life time prevalence of self-harm from 13\% to 25\% (Klonsky, 2011). The most 
frequently referred methods for self-harm were cutting or scratching and the most frequently used body areas were arms, legs and belly. They mentioned feelings of anger, sadness, anxiety, disgust and fear before the self-harming behavior, anger, sadness and fear during and sadness, relief and fear after. These results were also consistent with other studies (Nock, Gordon, Lloyd-Richardson, \& Prinstein, 2006).

There are several noteworthy limitations that should be considered when interpreting these findings. First, measures were self-reported and may reflect biases, especially underreporting of sensitive information. Second, the data represented students in high-school and university and may not be generalized to Portuguese young people or those who have dropped out of school. Third, analyses were based on cross-sectional data, which do not allow temporal ordering between correlates and outcomes. Accordingly, the analyses simply addressed the extent to which protective and risk factors correlates were associated with the outcome variable of interest. Fourth, the study did not assess other potential factors or mediators that may have been important in the associations examined. Several important factors such as the use of coping strategies, cognitive functioning and communication strategies in addition to past help-seeking were not available within the existing dataset but could have been helpful in the explanation of factors associated with self-harming behavior.

Despite these limitations, the findings from this study can be used to empirically document a relatively high overlap between self-harm among young people. Moreover, it appears that there are shared and unique factors that may be incorporated in future research and prevention programs of self-harm behavior among vulnerable young people. Unfortunately, public health prevention strategies that specifically address self-harm in populations of young people are not available in Portugal. However, there are several different types of programs that may have some success in addressing self-harming behavior either by directly addressing self-harm or indirectly by addressing the associated risk factors.

Despite the increased interest and pursuit of research into self-harm, its etiology and epidemiology, many aspects of self-harm remain relatively poorly understood. As such, future research is clearly needed to better understand and respond to the growing need of youth who experience self-harming behavior. One of the key barriers to progress in this field is the scarcity of available data sources that have included measures of self-harm. A recommendation for future data collections is to incorporate measures of self-harm, particularly among adolescents and young adults, so that the prevalence and epidemiology of self-harm can be studied across a range of populations and settings. Finally, while self-harm is clearly a complex and multi-faceted problem, efforts that seek to understand this issue better and that find ways to develop prevention and intervention strategies are sorely needed.

\section{Conclusions}

This study marks a needed step forward in assessing self-harming behavior prevalence and practices in a sample of adolescents and young adults. Findings suggested that educators, medical providers and therapists see a significant number of adolescents and young adults whom they may fail to recognize as self-harmers. Some of these are at heightened risk for severe distress and suicide-related behaviors. The reticence of those who practice self-harming behavior to seek advice from anyone makes it critical that medical and mental health providers find effective strategies for recognizing, treating, and preventing self-harming behavior. Results pointed out that self-harming behavior is related to other risk behaviors that may be addressed by means of universal interventions, in school and in the community, aiming at helping young people to choose and keep a healthy lifestyle and helping them increase their perception of well being and health related to quality of life. However results also suggested that self-harm is sometimes "used" as a way to calm down or conversely to keep up, that is to say to regulate one's emotions, This fact calls for specific interventions aiming at supporting young people finding alternative ways to recognize and deal with their own emotions without self-harming or adopting risk behaviors. In light of the current evidence, more research into the root causes, detection, prevention, and treatment of self-harm behavior is a public health imperative. 


\section{References}

Alfonso, M., \& Dedrick, R. F. (2010). Self-injury among early adolescents. American Journal of Health Education, 41, 74-84.

Chapman, A. L., Gratz, K. L., \& Brown, M. Z. (2006). Solving the puzzle of deliberate self-harm: The experiential avoidance model. Behavior Research and Therapy, 44 (3), 371-394.

Croyle, K., \& Waltz, J. (2007). Subclinical Self-Harm: Range of Behaviors, Extent and Associated Characteristics. American Journal of Orthopsychiatry, 17 (2), 332-342.

Currie C., Hurrelmann K., Settertobulte W., Smith R., \& Todd, J. (2000). Health and health behavior among young people. Copenhagen: World Health Organization.

Currie, C., Roberts, C., Morgan, A., \& Smith, R. (2004). Young people's health in context: international report from the HBSC 2001/02 survey. In WHO policy series: Health policy for children and adolescents. Copenhagen: WHO regional office for Europe.

Glassman, L. H., Weierich, M. R., Hooley, J. M., Deliberto, T. L., \& Nock, M. K. (2007). Child maltreatment, non-suicidal self-injury, and the mediating role of self-criticism. Behaviour Research and Therapy, 45 (10), 2483-2490.

Hamza, C. A., Stewart, S. L., \& Willoughby, T. (2012). Examining the link between nonsuicidal self-injury and suicidal behavior: A review of the literature and an integrated model. Clinical Psychology Review, $32,482-495$.

Hamza, C. A., Willoughby, T., \& Good, M. (in press). A preliminary examination of the specificity of the functions of nonsuicidal self-injury among a sample of university students. Psychiatry Research.

ISSS - International Society for the Study of Self-injury (2010). Definitional issues surrounding our understanding of self-injury. Retrieved 9/10/2012, from http://www.isssweb.org/

Jacobson, C. M., \& Gould, M. (2007). The epidemiology and phenomenology of non-suicidal self-injurious behavior among adolescents: A critical review of the literature. Archives Suicide Research, 11, 129-147.

Klonsky, E. D. (2011). Non-suicidal self-injury in United States adults: prevalence, sociodemographics, topography and functions. Psychological Medicine, 41, 1981-1986. doi:10.1017/S0033291710002497

Klonsky, E. D. (2009). The functions of self-injury in young adults who cut themselves: clarifying the evidence for affect-regulation. Psychiatry Research, 166, 260-268.

Matos, M.G., \& Equipa Aventura Social (in press). Self-injury in Portuguese students. Lisbon: FMH/UTL/ CMDT-UNL.

Matos, M. G, Ramiro, L., Reis, M., \& Equipa Aventura Social (2012). Online Study of Young People's Sexuality Report (OSYS). Lisbon: FMH/UTL/CMDT-UNL.

Matos, M. G., Simões, C. Tomé, G., Camacho, I., Ferreira, M., Ramiro, L., Reis, M., \& Equipa Aventura Social (2011). A Saúde dos Adolescentes Portugueses - Relatório do Estudo HBSC 2010. [The Health of Portuguese adolescents - HBSC Study Report 2010.] Lisbon: ACS/FMH/UTL/CMDT-UNL.

Moran, P., Coffey, C., Romaniuk, H., Olsson, C., Borschmann, R., Carlin, J., \& Patton, G. (2012). The natural history of self-harm from adolescence to young adulthood: a population-based cohort study. Lancet, $379,236-243$.

Muehlenkamp, J. J., Engel, S. G.,Wadeson, A., Crosby, R. D.,Wonderlich, S.A., Simonich, H., \& Mitchell, J. E. (2009). Emotional states preceding and following acts of nonsuicidal self-injury in bulimia nervosa patients. Behaviour Research and Therapy, 47 (1), 83-87.

Nock, K., Gordon, H., Lloyd-Richardson, E. \& Prinstein, J. (2006). Non-suicidal self-injury among adolescents: Diagnostic correlates and relation to suicide attempts. Psychiatry Research, 144, 65-72.

Nock, M. K. (2009). Why do people hurt themselves? New insights in to the nature and function of self-injury. Current Directions in Psychology, 18,78-83.

Whitlock, J., \& Knox, K. L. (2007). The relationship between self-injurious behavior and suicide in a young adult population. Archives of Pediatrics \& Adolescent Medicine, 161, 634-640.

Whitlock, J., Eckenrode, J., \& Silverman, D. (2006). Self-injurious behaviors in a college population. Pediatrics, 117, 1939-1948. 
Whitlock, J. L., Muehlenkamp, J., \& Eckenrode, J. (2008). Variation in non-suicidal self-injury: Identification of latent classes in a community population of young adults. Journal of Clinical Child and Adolescent Volume 4, 2012 Psychology, 37 (4). 725-735.

Yates, T. M. (2004). The developmental psychopathology of self-injurious behavior: Compensatory regulation in posttraumatic adaptation. Clinical Psychological Review, 24, 35-74.

Advised by Maria Ledzińska, University of Warsaw, Poland

\begin{tabular}{cl}
\hline Margarida Gaspar de Matos & PhD, Full Professor, Clinical and Health Psychologist, Technical University of Lisbon, \\
& CMDT \& Aventura Social Project, Estrada da Costa - Cruz, Quebrada, Portugal. \\
& E-mail: mmatos@fmh.utl.pt \\
& Website: http://www.aventurasocial.com
\end{tabular}

